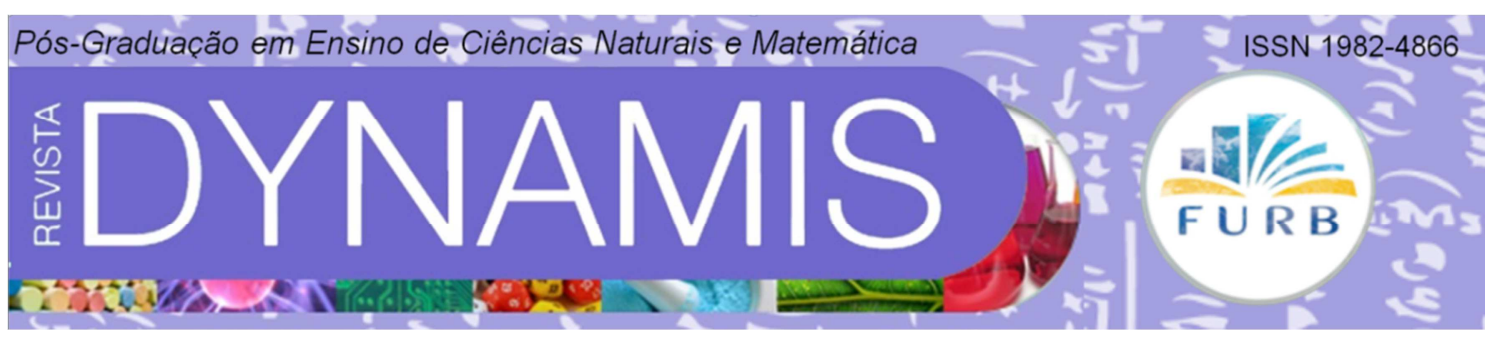

\title{
EDITORIAL
}

Prezado/a leitor/a,

Apresento a edição v. 21, n. 1, do primeiro semestre de 2015 com novidades para Revista Dynamis. Neste volume compartilhamos, além das pesquisas em contextos de escolas e universidades brasileiras nas áreas de ensino de Biologia, Matemática e Química, experiências de pesquisadores com interfaces entre coletivos de outros países, no estudo de suas políticas curriculares e em parcerias de trabalho e investigação.

Nesta direção, Barbosa e Cassiani nos convidam a refletir sobre aspectos referentes ao contexto histórico de uma construção curricular e sua implantação no artigo Efeitos de colonialidade no currículo de ciências do Ensino Secundário em Timor-Leste, a partir de uma investigação de documentos nacionais do país e na literatura.

Em outro contexto, com uma parceria entre os países Espanha-Brasil, os pesquisadores Torres e Silva compartilham uma proposta de pensar o ensino e a formação docente pela Ecoformação e transdisciplinaridade na Rede de Escolas Criativas - RIEC evidenciando um trabalho colaborativo com foco no reconhecimento e difusão do potencial inovador e criativo da escola do século XXI.

No cenário brasileiro, Rehfeldt, Hauschild, Quartieri, Giongo e Azambuja em $O$ uso de softwares, tabelas e planilhas nas práticas laborais de engenheiros apresentam resultados parciais da pesquisa "Formas de vida, jogos de linguagem e currículo: implicações para o ensino de Engenharia", em desenvolvimento num Centro Universitário. No artigo, as autoras destacam depoimentos de um grupo de engenheiros sobre como usam a Matemática para resolver situações-problemas dos seus cotidianos.

Os/as autores/as Rodrigues, Morais, Simões Neto e Silva apresentam Uma abordagem do tema biodiesel no Ensino Médio utilizando uma situação-problema a partir de uma investigação com estudantes do $3^{\circ}$ ano da rede pública estadual de Pernambuco. Com isso, evidenciam contribuições da investigação-ação para compreensão destes sujeitos de conceitos relativos ao biodiesel e suas interfaces com os conceitos de Química.

Ainda, no contexto da Educação Básica, Barauna e seu coletivo de estudantes socializam uma Metodologia alternativa no processo de ensino aprendizagem sobre Embriologia e reprodução humana para alunos do ensino médio das escolas de Blumenau, pesquisa originada de um trabalho de extensão universitária com objetivo de contribuir para aprendizagem de estudantes adolescentes e de sua comunidade de conceitos relacionados ao estudo da Biologia do corpo humano. 
No sentido da reflexão epistemológica, Venturi discute a problemática que envolve o ensino-aprendizagem da Educação em Saúde no Ensino de Ciências, empregando argumentos e fundamentos nos perfis conceituais (Mortimer) e perfis espitemológicos (Bachelard), modelos cognitivos que explicam a aprendizagem, a forma de compreensão e ação dos alunos, integrando o contexto neste processo, o que resultou na pesquisa Discussões epistemológicas: contribuições para a educação em saúde realizada no ensino de Ciências.

Finalizo este editorial agradecendo aos/as autores/as que confiaram as suas pesquisas para divulgação na Dynamis e aos nossos pareceristas, que disponibilizaram de seus tempos para leitura e avaliação dos trabalhos.

Agradeço também a você, caro/a leitor/a, que possibilita, pela sua leitura, que nossa Revista cumpra a sua missão em dinamizar o intercâmbio de ideias e práticas da pesquisa em Educação Científica.

Boa leitura!

\section{Daniela Tomio}

Editora-chefe da Revista Dynamis Universidade Regional de Blumenau - FURB danitomiobr@gmail.com 